\title{
A RARE CASE OF NEPHROTIC SYNDROME IN CARDIAC PATIENTS
}

\author{
C Bharath Kumar Goud, A Rama Krishnaudu, M.V.S. Subbalaxmi
}

\section{ABSTRACT}

Introduction: Renal disease due to infective endocarditis (IE) is well established, with the earliest reports of glomerular lesions published over 100 years ago. Although initially believed to be primarily embolic it later became clear that over $80 \%$ of cases represented focal, segmental, or diffuse proliferative glomerulonephritis (GN) with prominent endocapillary proliferation and occasional infiltrating leukocytes. However, the literature describing nephritis associated with IE still relies heavily on autopsy studies conducted in the pre- and early post-antibiotic era or small renal biopsy studies from the 1970s.Over the past decades, IE outcomes have not improved, and infection rates are steadily increasing.

Case Report: This thirty seven year old female patient came to OPD with chief complaints of facial puffiness, abdominal distension, swelling of feet, numbness of head since one month duration. She also complained of shortness of breath (SOB) which was insidious onset and gradually progressive NYHA Class 2. She was non-diabetic and non-hypertensive. She was anemic with bilateral pitting edema. She also had significant thyromegaly. Her cardiovascular examination revealed a regular, normo-volemic pulse at a rate of $120 \mathrm{bpm}$, blood pressure of 170/100 $\mathrm{mm}$ of $\mathrm{Hg}$. On auscultation, both heart sounds were normally audible with early diastolic high pitched murmur heard best in left $2^{\text {ndintercostal space during }}$ expiration. 2-dimensional echocardiography showed mild Aortic regurgitation with vegetation on the aortic valve. Her routines showed she was anemic, proteinuric (2400mg in $24 \mathrm{hr}$ urine) with hypo-albuminemia (albumin:1.4g/l), hypothyroid, and hyperlipidemic (total cholesterol:408mg/dl). Her renal parameters were suggestive of pre-renal azotemia with serum urea of $40 \mathrm{mg} / \mathrm{dl}$. These findings led to a diagnosis of nephrotic syndrome. Her blood and urine culture showed negative findings. She underwent renal biopsy. Electron microscopic study of a renal biopsy specimen was suggestive of Focal Segmental Glomerulosclerosis. Her collagen profile was not suggestive of any collagen vascular disease.

She was started on immunosuppressive therapy for recurrent relapses. She had an episode of short duration weakness of left upper limb from which she recovered spontaneously within 10 minutes. Two-dimensional echocardiography and Trans-

Article received on 22 MAR 2017, published on 30 APR 2017.

C Bharath Kumar Goud ${ }^{1}$, A Rama Krishnaudu ${ }^{2}$, M.V.S. Subbalaxmi ${ }^{3}$

${ }^{1}$ Senior Resident, Department of Cardiology, NIMS, India

${ }^{2}$ Asst.Prof, Department of Cardiology, NIMS, India

${ }^{3}$ Additional Prof, Department of General Medicine, NIMS, India

Corresponding Author: C. Bharath Kumar Goud

Email: chukkala_mbbs21@yahoo.com esophageal echocardiography showed healed vegetation over non-coronary cusp of aortic valve. Nephrologist opinion was taken regarding the nephrotic syndrome and healed vegetation over non-coronary cusp.

Conclusion: Nephrotic syndrome being immunodeficient state may lead to infective endocarditis in underlying valvular predisposing condition. Complementary to this subacute endocarditis may lead to nephrotic range proteinuria due to deposition of complements in glomeruli leading to massive proteinuria in some patients.

In this case, the patient presented with nephrotic syndrome with recurrent remissions and relapses which are quite a rare entity and further cases have to be studied regarding the implications of this complication in the management of nephrotic syndrome and infective endocarditis.

Keywords: Nephrotic syndrome.

\section{INTRODUCTION}

Renal disease due to infective endocarditis (IE) is well established, with the earliest reports of glomerular lesions published over 100 years ago [1, 2,3]. Although initially believed to be primarily embolic $[1,2,3]$ it later became clear that over $80 \%$ of cases represented focal, segmental, or diffuse proliferative glomerulonephritis (GN) with prominent endocapillary proliferation and occasional infiltrating leukocytes $[4,5,6]$. However, the literature describing nephritis associated with IE still relies heavily on autopsy studies conducted in the preand early post antibiotic era or small renal biopsy studies from the 1970s.

Several reviews have emphasized the evolution occurring in recent decades in renal complications of infectious diseases in general, with particular emphasis on the change in demographics from younger to older patients, the frequency of comorbidities such as diabetes and HIV, and the change in predominance of infectious agents from primarily streptococcal to a broader array of organisms with predominance of Staphylococci $[7,8,9,10]$. IE occurs in 30 to $60 \%$ of patients with Staphylococcus aureus bacteremia and carries a mortality rate of $40-50 \%$ [11]. Over the past decades, IE outcomes have not improved, and infection rates are steadily increasing [11]. 


\section{CASE REPORT}

This thirty seven year old female patient came to OPD with chief complaints of facial puffiness, abdominal distension, swelling of feet, numbness of head since one month duration. She also complained of shortness of breath (SOB) which was insidious onset and gradually progressive NYHA Class 2. SOB was not associated with chest pain, palpitations, orthopnea or paroxysmal nocturnal dyspneic episodes. She doesn't complain of any recent decrease in urine output, dysuria, dark colored urine or fever with rash or arthralgias. There was no weight-gain.

She was non-diabetic and non-hypertensive. She didn't give any significant history of cardiovascular or cerebrovascular disease. She was not on any thyroid hormone replacement therapy. She attained menarche at age of 13 with regular cycles She is a mother of two children born of spontaneous conceptions and her pregnancies and post-partum periods were uneventful. She was anemic with bilateral pitting edema. She also had significant thyromegaly. There was no lymphadenopathy or Hepato-splenomegaly. She didn't have any clubbing or central/peripheral cyanosis. Her cardiovascular examination revealed a regular, normovolemic pulse at rate of $120 \mathrm{bpm}$, blood pressure of 170/100 $\mathrm{mm}$ of $\mathrm{Hg}$. On auscultation both heart sounds were normally audible with early diastolic high pitched

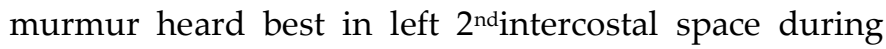
expiration.

She was admitted to general medicine department for further evaluation of anasarca and management. Her routines showed she was anemic, protein uric $(2400 \mathrm{mg}$ in $24 \mathrm{hr}$ urine) with hypoalbuminemia (albumin:1.4g/l), hypothyroid, and hyperlipidemic (total cholesterol:408mg/dl). Her renal parameters were suggestive of pre-renal azotemia with serum urea of $40 \mathrm{mg} / \mathrm{dl}$. These findings led to a diagnosis of nephrotic syndrome. Her blood and urine culture showed negative findings.

Based on these parameters patient was transferred to nephrology department for further evaluation. She underwent renal biopsy. Electron microscopic study of a renal biopsy specimen showed 7 glomeruli. Most of these showed normal in size and cellularity with the normal basement membrane. One glomerulus showed little evidence of immune complex in the glomeruli with segmental sclerosis and GBM was of normal thickness which were suggestive of Focal Segmental Glomerulosclerosis. Her collagen profile was not suggestive of any collagen vascular disease.

She was discharged on diuretic and angiotensin-receptor blockers for Proteinuria and fluid retention. She was given thyroid hormone replacement and statin therapy. Her follow-up period over 4 years showed remissions with steroid therapy and frequent relapses with tapering of steroids. She was started on immunosuppressive therapy.

She had an episode of short duration weakness of left upper limb from which she recovered spontaneously within 10 minutes. She was evaluated for this by stroke protocol. Magnetic resonance imaging showed lacunar infarcts and was diagnosed as Cheval syndrome. Twodimensional echocardiography and Trans-esophageal echocardiography showed healed vegetation over noncoronary cusp of aortic valve. Nephrologist opinion was taken regarding the nephrotic syndrome and healed vegetation over non-coronary cusp. Nephrotic syndrome being immune deficient state may lead to infective endocarditis in underlying valvular predisposing condition. Complementary to this subacute endocarditis may lead to nephrotic range Proteinuria due to deposition of complements in glomeruli leading to massive Proteinuria in some patients.

MRI showing lacunar infarcts.

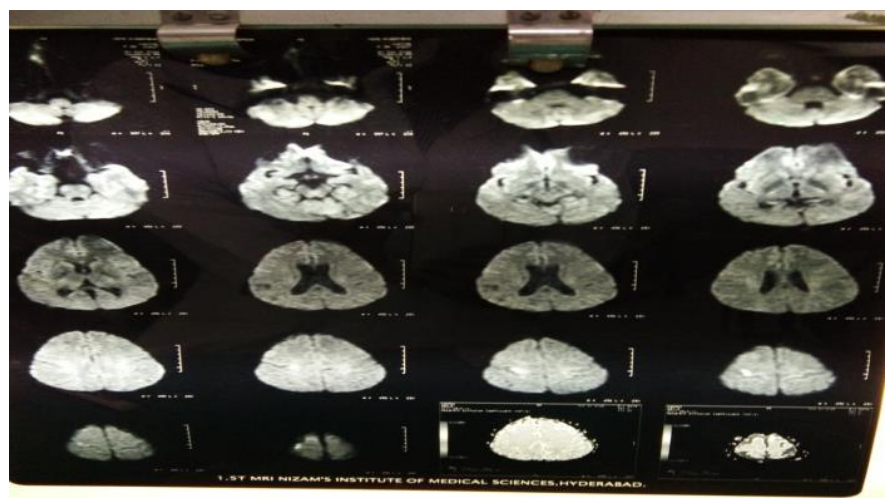

Biopsy specimen showing FSGS.

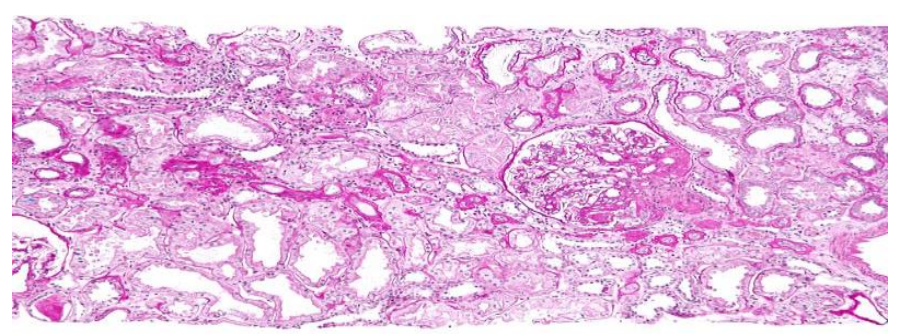




\section{DISCUSSION}

Endocarditis refers to endothelial damage with thrombosis on endocardial surfaces, typically on the heart valves. Two major types of endocarditis exist infectious endocarditis, which has a microbial etiology, and noninfectious endocarditis.

The population-based incidence of endocarditis is 4-10 per 100,000 per year, with a slightly higher rate in men. $[12,13]$ The death rate due to endocarditis has been estimated at 1 per 100,000 per year, and it is greater than 10 times that amount in an urban population with a high rate of intravenous drug abuse (IVDA)[14]. Endocarditis accounts for about 0.75 admissions per 1000 per year in large community hospitals [15].

The complication of arterial embolization is second in frequency to congestive heart failure for both sub-acute and acute IE. The frequency of this complication has decreased, from $80 \%$ in the pre-antibiotic era to $15-35 \%$ today. The emboli are usually sterile because of the minimally invasive nature of the causative organisms.

Patients with infective endocarditis (IE) can develop several forms of renal disease: a bacterial infectionrelated immune complex-mediated glomerulonephritis, which can also occur with an infected ventriculo-atrial shunt [16-19]. In addition, a drug-induced acute interstitial nephritis or, with aminoglycosides, acute kidney injury (due to acute tubular necrosis) can develop.

The frequency of renal involvement in patients was illustrated in a retrospective study of over 200 consecutive episodes of bacterial endocarditis [21]. Approximately one-third of patients developed acute kidney injury (of any cause), a complication observed most often among older patients and those with Staphylococcus aureus infection.

The most common biopsy finding was necrotizing and crescentic GN (53\%), followed by endo-capillary proliferative GN (37\%). C3 deposition was prominent in all cases, whereas IgG deposition was seen in $<30 \%$ of cases. Most patients had immune deposits detectable by electron microscopy. Thus, IE-associated GN most commonly presents with AKI.

In this case, the patient presented with nephrotic syndrome with recurrent remissions and relapses which are quite a rare entity and further cases have to be studied regarding the implications of this complication in management of nephrotic syndrome and infective endocarditis.

\section{REFERENCES}

1. LohleinM. Ueberhāmorrhag is chenieren affektioned beichronis cherul zerözerendo karditis. Med Klin. 1910;6:375-379.

2. Baehr G. Glomerular lesions of subacute bacterial endocarditis. J Exp Med.1912;15:330-347.[PMC free article] [PubMed]

3. Bell ET. Glomerular lesions associated with endocarditis. Am J Pathol. 1932;8:639-669.[PMC free article] [PubMed].

4. Eknoyan G, Lister BJ, Kim HS, et al. Renal complications of bacterial endocarditis. Am J Nephrol. 1985;5:457-469. [PubMed].

5. Fernandez Guerrero ML, Alvarez B, Manzarbeitia F, et al. Infective endocarditis at autopsy: a review of pathologic manifestations and clinical correlates. Medicine ～(Baltimore, MD) 2012;91:152164.[PubMed]

6. Neugarten J, Baldwin DS. Glomerulonephritis in bacterial endocarditis. Am J Med. 1984;77:297304.[PubMed]

7. Nasr SH, Radhakrishnan J, D'Agati VD. Bacterial infection-related glomerulonephritis in adults. Kidney Int. 2013;83:792-803. [PubMed]

8. Couser WG, Johnson RJ. The etiology of glomerulonephritis: roles of infection and autoimmunity. Kidney Int. 2014;86:905-914. [PubMed]

9. Nasr SH, Fidler ME, Valeri AM, et al. Post infectious glomerulonephritis in the elderly. J Am Soc Nephrol. 2011;22:187-195. [PubMed]

10. Nadasdy T, Hebert LA. Infection-related glomerulonephritis: understanding mechanisms. Semin Nephrol. 2011;31:369-375. [PubMed] 
11. Bor DH, Wool handler S, Nardin R, et al. Infective endocarditis in the U.S., 1998-2009: a nationwide study. PLoS One. 2013; 8:e60033. [PMC free article] [PubMed]

12. Fonager K, Lindberg J, Thulstrup AM, Pedersen L, Schønheyder HC, Sørensen HT. Incidence and shortterm prognosis of infective endocarditis in Denmark, 1980-1997. Scand J Infect Dis. 2003. 35(1):27-30. [Medline]

13. Walpot J, Blok W, van Zwienen J, Klazen C, Amsel B. Incidence and complication rate of infective endocarditis in the Dutch region of Walcheren: a 3-year retrospective study. Acta Cardiol. 2006 Apr. 61(2):17581. [Medline].

14. Burke AP, Kalra P, Li L, Smialek J, Virmani R. Infectious endocarditis and sudden unexpected death: incidence and morphology of lesions in intravenous addicts and non-drug abusers. J Heart Valve Dis. 1997 Mar. 6(2):198-203. [Medline].

15. Watanakunakorn C, Burkert T. Infective endocarditis at a large community teaching hospital, 1980-1990. A review of 210 episodes. Medicine (Baltimore). 1993 Mar. 72(2):90-102. [Medline].
16. Neugarten J, Baldwin DS. Glomerulonephritis in bacterial endocarditis. Am J Med 1984; 77:297.

17. Arze RS, Rashid H, Morley R, et al. Shunt nephritis: report of two cases and review of the literature. ClinNephrol 1983; 19:48.

18. Rose, BD. Pathophysiology of Renal Disease, 2nd ed, McGraw-Hill, New York City 1987. p.229.

19. Haffner D, Schindera F, Aschoff A, et al. The clinical spectrum of shunt nephritis. Nephrol Dial Transplant 1997; 12:1143.

20. MajumdarA, Chowdhary S, Ferreira MA, et al. Renal pathological findings in infective endocarditis. Nephrol Dial Transplant 2000; 15:1782.

21. Conlon PJ, Jefferies F, Krigman HR, et al. Predictors of prognosis and risk of acute renal failure in bacterial endocarditis. ClinNephrol 1998; 49:96. 